\title{
CONFERÊNCIA INTERNACIONAL NA FAUUSP CIDADES SUSTENTÁVEIS: DO PROJETO URBANO ÀS EDIFICAÇÕES
}

\author{
Joana Carla Soares Gonçalves
}

As reflexões sobre o tema "Cidade sustentável", mediante uma perspectiva ambiental da arquitetura e do urbanismo, têm ressaltado, nas últimas duas décadas, a urgência da eficiência energética das edificações e dos meios de transportes, assim como o menor consumo e manejo consciente das águas, além das vantagens do transporte público e da importância de nichos ecológicos e espaços públicos convidativos e de qualidade ambiental. Nesse sentido, cresce o entendimento que os ganhos ambientais e energéticos no ambiente construído repercutem-se diretamente em benefícios para as dinâmicas socioeconômicas da vida urbana.

Neste contexto, a conferência Cidades Sustentáveis: Do Projeto Urbano às Edificações, realizada na Faculdade de Arquitetura e Urbanismo da Universidade de São Paulo, em 20 e 21 de junho de 2007, teve como objetivo geral contribuir para a discussão de questões do planejamento, do desenho urbano, da arquitetura e da engenharia relacionadas à sustentabilidade das cidades.

O seminário foi promovido pela Nova Técnica Editorial Ltda., Redação e Publicidades, e contou com apoio da Faculdade de Arquitetura e Urbanismo e do Núcleo de Tecnologia da Arquitetura e do Urbanismo da Universidade de São Paulo, e ainda, do Instituto dos Arquitetos do Brasil de São Paulo. O público-alvo foi definido por representantes do poder público, de grupos de pesquisa e, ainda, por agentes do projeto e do mercado da construção civil.

Com o foco na problemática da sustentabilidade do projeto urbano às edificações, pesquisadores e profissionais de renome, especialistas em cada uma das disciplinas selecionadas como temas para a discussão, abordaram em uma série de palestras, desde assuntos sobre planejamento estratégico e estratégias de adensamento urbano até o impacto ambiental da construção civil, tecnologias prediais e métodos de projeto para auxiliar nas avaliações de desempenho ambiental de edifícios. Nesse sentido, o evento trouxe palestras com uma orientação predominantemente técnica, enriquecida com temas institucionais e conceituais, como o financiamento a projetos auto-sustentáveis e políticas públicas, assim como com a apresentação de estudos de caso nacionais e internacionais.

Tendo em vista o futuro da cidade moderna e de seus edifícios, foram exploradas idéias embasadas em avanços tecnológicos e de método, somadas à análise de propostas para o crescimento e o desenvolvimento do ambiente construído, na busca por um menor impacto ambiental na arquitetura e na engenharia predial. No conteúdo das palestras foram expostas experiências nacionais e internacionais que serviram de base para uma visão ampla sobre os desafios e as possibilidades do projeto. Dentre os palestrantes estavam presentes pesquisadores da Universidade de São Paulo, da Universidade de Campinas e especialistas de instituições de pesquisa e projeto do Reino Unido. 
Figura 1: Imagem de divulgação do seminário Cidades Sustentáveis Crédito: NT Editorial
Figura 2: Auditório Ariosto Milla no seminário Cidades Sustentáveis, 20 e 21 de junho de 2007, FAUUSP

Crédito: NT Editorial

Figura 3: Mesa final de debates com os palestrantes convidados Crédito: NT Editorial

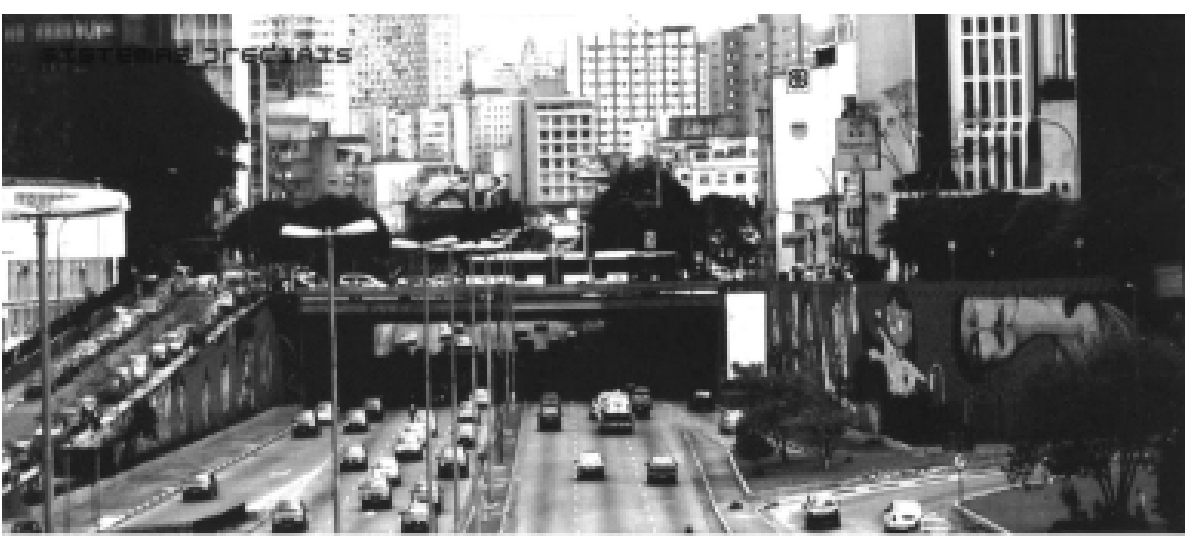

\section{Brasil entra no circuito de discussão da arquitetura sustentável}

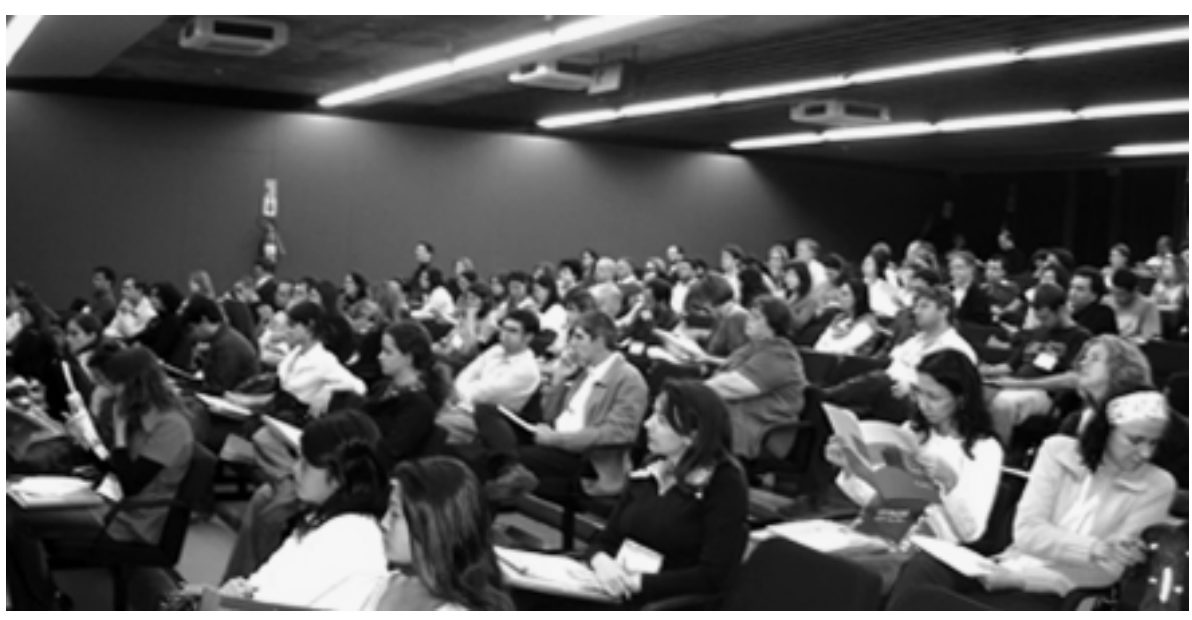

pós- $\mid \begin{aligned} & \varpi \\ & -1\end{aligned}$

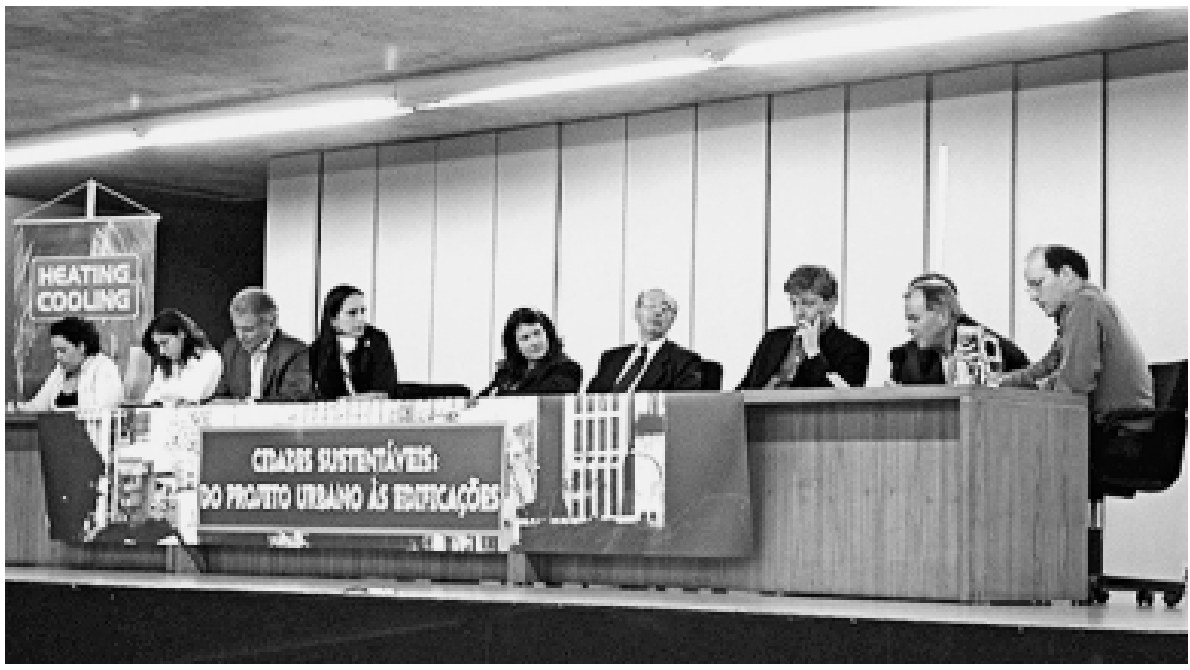


No que diz respeito ao contexto internacional, o seminário contou com a presença de três convidados, representantes de instituições sediadas em Londres, bastante atuantes em projetos, pesquisas e fóruns sobre questões de sustentabilidade urbana.

O primeiro deles a expor foi o arquiteto e urbanista Donald van Dansik, exdiretor do escritório OMA (Office for Metropolitan Architecture), ao lado de Rem Koolhaas, em Roterdã, e ex-professor da Technical University of Eindhoven. Donald van Dansik foi um dos fundadores do escritório de arquitetura e projetos urbanos One Architecture, em Amsterdã, e atualmente atua na área de consultorias para projetos urbanos, com destaque para uma série de cidades da Europa e da Ásia.

O segundo convidado internacional foi Daniel Kozak, arquiteto e urbanista da Universidade de Buenos Aires, doutorando da instituição de pesquisa School of the Built Environment, Oxford Brookes University, no Reino Unido, e membro do centro de pesquisas Research Centre Habitat \& Energy (CIHE), da Faculdade de Arquitetura, Design e Urbanismo da Universidade de Buenos Aires, Argentina. Daniel Kozak é co-autor da publicação World cities' and urban form: Fragmented, polycentric, sustainable? (no prelo).

$\mathrm{O}$ engenheiro ambiental Klaus Bode foi o terceiro palestrante estrangeiro, fundador e diretor do escritório de engenharia e consultoria BDSP Partnership, em Londres, especializado nas áreas de conforto ambiental e eficiência energética do edifício e do espaço urbano. Dentre os exemplos recentes do trabalho do BDSP, deve-se citar a Assembléia Nacional do País de Gales (arquitetura de Richard Rogers Partnership) e o projeto ZED (Zero $\mathrm{CO}_{2}$ Emissions), em colaboração com o escritório Future Systems Architects. Klaus Bode também é professor do curso de pós-graduação Environment and Energy, da Architectural Association Graduate School, em Londres.

As palestras internacionais abordaram os seguintes temas:

- Sustainable urban planning: designing with water, por Donald van Danzig;

- Architecture and urban design towards more sustainable cities, por Daniel Kozak; e

- Environment and energy for urban sustainability: technology, tools and design strategies, por Klaus Bode.

Paralelamente, o corpo de palestrantes brasileiros foi composto pelos professores doutores da FAUUSP: Siegbert Zanettini, Regina Meyer, Joana Carla Soares Gonçalves e Denise Duarte; pelo professor doutor da Escola Politécnica da USP, Orestes Marracini Gonçalves; pela professora doutora da UNICAMP, Vanessa Gomes Silva; pela arquiteta e especialista em projetos de iluminação Esther Stiller; pela arquiteta e urbanista e doutora pela FAUUSP, Lúcia Pirró; e pelo engenheiro de instalações prediais Francisco de Assis Dantas, de Recife. As palestras nacionais trouxeram os seguintes temas para o debate:

- São Paulo: Os desafios da metrópole para a sustentabilidade urbana, por Regina Meyer;

- Densidade x qualidade ambiental: estratégias para a revitalização de áreas urbanas consolidadas, por Denise Duarte e Joana Carla Soares Gonçalves;

- Projeto de arquitetura voltado à conservação de energia, por Lúcia Pirró;

- Conforto ambiental e o uso racional de energia, por Francisco de Assis Dantas; 
- Iluminação: bem-estar, arte e ciência, por Esther Stiller;

- Uso racional de água, por Orestes Marracini Gonçalves;

- Uso de materiais ambientalmente sustentáveis; por Vanessa Gomes;

- O projeto de eco-eficência do CENPES II, o novo Centro de Pesquisas da

Petrobrás, no Rio de Janeiro: Uma atitude ambiental inovadora na arquitetura

brasileira, por Joana Carla Soares Gonçalves e Denise Duarte; e

- Arquitetura brasileira, por Siegbert Zanettini.

Abrindo as apresentações, Donald van Danzig trouxe para a discussão o conceito de planejamento sustentável, ilustrado com casos holandeses, em que os planos de ocupação urbana são desenvolvidos ao redor das estratégias de adensamento e diversidade. Complementando, é dito que, de forma geral, as questões de ordem ambiental têm forçado um novo foco no desenvolvimento urbano.

Falando especificamente de São Paulo e dos desafios das grandes metrópoles diante das considerações sobre sustentabilidade, a professora doutora e pesquisadora da FAUUSP Regina Meyer chamou a atenção para o contraste das concentrações populacionais fora das áreas de adensamento do ambiente construído, desprovidas da infra-estrutura urbana necessária, sendo uma das conseqüências dessa disparidade o funcionamento de setores dessa infra-estrutura urbana aquém de sua capacidade. Como exemplo disso, um dos bairros menos adensados da cidade é o Centro. Paralelamente, a professora apontou para o fato de a cidade de São Paulo viver um dos momentos mais predatórios do uso do espaço urbano, residual da cidade industrial.

No âmbito do edifício e dos aspectos do conforto e da energia, a especialista em projetos de luminotécnica Esther Stiller abordou o papel da iluminação na criação de ambientes saudáveis. Para a especialista, um projeto de iluminação artificial deve ser concebido pelo tripé: arte, ciência e responsabilidade ambiental. No que cabe à tecnologia, Esther destacou a importância da qualidade do sistema para o sucesso do projeto e ressaltou que o compromisso com a sustentabilidade, na esfera do projeto de iluminação artificial, implica lidar com detalhadas avaliações de desempenho.

Com vistas à materialidade do projeto arquitetônico, a professora doutora e pesquisadora da FAUUSP Vanessa Gomes Silva abordou o tema do impacto ambiental dos materiais e as etapas do processo de projeto. Vanessa Silva alerta para a complexidade do tema, dentre outros fatores, pelo grande número de variáveis envolvidas no ciclo de vida de um componente construtivo, a falta de dados disponibilizados pela indústria da construção e a conseqüente dificuldade na especificação de materiais em prol de um menor impacto ambiental.

A palestra sobre densidade e qualidade ambiental, proferida pelas professoras doutoras da FAUUSP Denise Duarte e Joana Gonçalves, fez a ponte entre os aspectos urbanos e arquitetônicos da sustentabilidade. Com a apresentação de um projeto de pesquisa, ainda de caráter exploratório e preparatório para um estágio mais preciso e de maior rigor, foi demonstrada a importância da interdependência entre edifícios e espaços abertos na conquista do desempenho ambiental da unidade de projeto, além de reforçar o papel da quadra urbana, e não do lote, na retomada do espaço público como lugar desejável socialmente, confortável e de alto valor ambiental. 
No universo dos estudos de caso de edificações, cabe destacar o caso brasileiro do novo Centro de Pesquisas da Petrobrás no Rio de Janeiro, CENPES II, projeto apresentado pelas professoras Joana Gonçalves e Denise Duarte. O projeto vencedor, de autoria da Zanettini Arquitetura S.A., com a participação de um grupo de consultores, contou com a colaboração da equipe de pesquisadores do Laboratório de Conforto Ambiental e Eficiência Energética, do Departamento de Tecnologia da Arquitetura da FAUUSP, encarregada das avaliações de desempenho ambiental da proposta. Fortemente influenciada pelo clima quente-úmido, o projeto mostra edifícios conectados por espaços de transição, enquanto coberturas sombreadas, elementos de sombreamento de fachadas, plantas estreitas e inércia térmica leve, para interagir com o clima. Desde o estágio conceitual, o projeto foi desenvolvido com base em avaliações de conforto térmico, iluminação, acústica e eficiência energética por meio de uma série de simulações computacionais.

De formal geral, todas as exposições convergiram para uma discussão sobre métodos e processos de projeto, em prol de soluções urbanas e de edificações mais sustentáveis.

O encerramento do evento se deu com uma mesa-redonda, da qual fizeram parte os palestrantes internacionais e nacionais. A discussão final sobre o futuro das cidades e as possibilidades para a sustentabilidade foi levantada, tomando como ponto de partida a questão norteadora sobre o conceito de sustentabilidade e sua aplicação no projeto. Nesse momento de fechamento dos debates, a participação do público foi significativa, pois chamou a atenção para a falta de uma integração efetiva entre três setores estruturais de nossas sociedades: a indústria da construção, o mercado e o universo das pesquisas e dos avanços tecnológicos.

Por parte dos integrantes da mesa, ressaltou-se a preocupação de esclarecer suas interpretações sobre os conceitos e aplicações de sustentabilidade, como algo mais complexo e comprometido com o equilíbrio ambiental, os benefícios sociais e a vitalidade das cidades do que 0 apresentado pelas facções do mercado imobiliário nos últimos anos, em cidades de acelerado crescimento populacional e da malha urbana, como São Paulo.

Seguramente, o debate instigou arquitetos, urbanistas e demais agentes do projeto a revisarem as estratégias e as práticas de processos de projeto convencionais que mantêm, ainda significativamente isolados, os vários integrantes do processo de projeto, dentro de suas respectivas áreas do conhecimento.

Paralelamente, as preocupações com o futuro da sustentabilidade das cidades nos motiva a questionar, reavaliar e aprender com o desempenho ambiental do legado arquitetônico nacional e internacional. Perante a necessidade da criação de paradigmas arquitetônicos e a busca de soluções apropriadas às demandas da atualidade e suas possibilidades tecnológicas no cenário nacional, o aperfeiçoamento técnico do profissional de projeto e o apoio por meio de regulamentações estaduais e federais, em prol do melhor desempenho ambiental das construções, concluíram as discussões.

\section{Joana Carla Soares Gonçalves}

Professora doutora da FAUUSP, Departamento de Tecnologia da Arquitetura e do Urbanismo, Laboratório de Conforto Ambiental e Eficiência Energética.

e-mail: jocarch@usp.br 